\title{
Histology of Fetal Ovary and Oviduct of One Humped Camel
}

\author{
Fatima Oyenike Oyelowo ${ }^{1 *}$, Mamman Legbo Sonfada ${ }^{2}$, Abubakar Abubakar Umar ${ }^{2}$, \\ Muhammad Salisu Abubakar ${ }^{3}$, Sani Abdullahi Shehu², Abubakar Danmaigoro² ${ }^{2}$ Ibrahim Wiam ${ }^{4}$, \\ Sunday Akau Hena ${ }^{5}$, Balkisu Banke Oyelowo ${ }^{6}$ and Taiwo Kamar-deen Bello ${ }^{7}$ \\ ${ }^{1}$ Department of Veterinary Anatomy, Faculty of Veterinary Medicine, University of Abuja, FCT, Abuja, NIGERIA \\ ${ }^{2}$ Department of Veterinary Anatomy, Faculty of Veterinary Medicine, Usmanu Danfodiyo University, Sokoto State, NIGERIA \\ ${ }^{3}$ Department of Veterinary Pathology, Faculty of Veterinary Medicine, Usmanu Danfodiyo University, Sokoto State, NIGERIA \\ ${ }^{4}$ Department of Veterinary Anatomy, Faculty of Veterinary Medicine, University of Maiduguri, Borno State, NIGERIA \\ ${ }^{5}$ Department of Veterinary Anatomy, Faculty of Veterinary Medicine, University of Jos, Plateau State, NIGERIA \\ ${ }^{6}$ Department of Veterinary Pharmacology and Toxicology, Faculty of Veterinary Medicine, Ahmadu Bello University, \\ Zaria, Kaduna State, NIGERIA \\ ${ }^{7}$ Biotechnology Research Programme, National Animal Production Research Institute, Zaria, Kaduna State, NIGERIA \\ "Corresponding author: FO Oyelowo; E-mail: fatima.oyenike@uniabuja.edu.ng
}

Received: 11 Nov., 2020

Revised: 21 Jan., 2021

Accepted: 29 Jan., 2021

\begin{abstract}
The main aim of this work was to study the histological development of fetal ovary and oviduct. The samples were collected from abattoir accidental findings over a period of six months. The ovary and oviduct samples were fixed and routinely processed with Haematoxylin and Eosin and Periodic Acid Schiff. Cortical and medullary zones were not so distinct at the first trimester ovarian tissue. Scanty follicles were found scattered within the connective tissue. The zones were more distinct in the second and most distinct in the third trimester. The primary follicles were also numerous along side with vessels. The oviduct had long branching folds bearing the pseudostratified epithelium that was clearly demarcated in the third trimester. It was concluded that these features can be added to the existing literature and Ultrastructure is recommended in the future research of fetal female Camelids.
\end{abstract}

\section{HIGHLIGHTS}

(0 Fetal ovaries of the camelids have no distinct zonal demarcation at the first trimester.

(0 Numerous blood vessels that increased across the trimesters were identified.

(0 Fetal oviduct had a pseudostratified epithelium bearing long branching folds.

(0 Fimbriae of the oviduct was distinct at the third trimester.

Keywords: Ovary, oviduct, histology, one humped camel, reproduction

The one humped camel is a unique domesticated animal with lots of advantages to human race and multipurpose by nature, it serves the purpose of meat, milk, wool, transport, race, agricultural work, and beauty contest (Faye, 2015; Al- Juboori, 2016). In some societies, people use camel as cultural heritage, others for agricultural activities and hunting (Volpato and Howard, 2014).

The reproductive potential of female animals are influences by the normal development and differentiation of the ovaries (Aruna, 2017). Albaghady, 2006 described the ovaries in young camels with follicular developments appearing as follicular wave. The uterine tubes which are also known to connected the ovaries to the uterus, alongside with the uterus offer a great diversity of morphological

How to cite this article: Oyelowo, F.O., Sonfada, M.L., Umar, A.A. Abubakar, M.S., Shehu, S.A., Danmaigoro, A., Wiam, I., Hena, S.A., Oyelowo, B.B. and Bello, T.K. (2021). Histology of fetal ovary and oviduct of one humped camel. J. Anim. Res., 11(1): 19-23. Source of Support: None; Conflict of Interest: None 
features in a wide range of species of animals with respect to their reproductive and evolutionary adaptation (Villalon et al., 1998). There is a dearth of information on the histological development of ovary and ovidut of fetal one humped camel. Thus the main aim of this research is to study the histological development of ovary and ovidut of fetal one humped camel found in theNorthern Nigeria.

\section{MATERIALS AND METHODS}

Accidental fetuses were sourced from the Sokoto and Kano Municipal abattoirs. The fetuses were dissected according to Habel (1970) method of dissection. The ovaries and oviducts were identified and about $1 \mathrm{~cm}^{3}$ samples of each were fixed in $10 \%$. The samples were processed using the paraffin method of embedding tissue as described by Bancroft (2002). The tissues were passed under different ascending grades of alcohol for 60 minutes and later dipped in absolute alcohol for another 60 minutes. For easy paraffin infiltration into the tissues, the samples were cleared with xylene twice. The samples were further infiltrated with the wax for 60 minutes and embedded as tissue blocks. 5-7 $\mu \mathrm{m}$ thickness sections were made serially and floated on a warm water bath for some seconds. At $37^{\circ} \mathrm{C}$, the sections were dried on slides for eight hours, cleared in xylene and finally rehydrated in grades of alcohol in descending order for $\mathrm{H} \&$ E or Periodic Acid Schiff.

For the $\mathrm{H} \& \mathrm{E}$, the sections were rinsed in water and further stained with Harris hematoxylin for 4 mins. Sections were rinsed under distilled water and immersed in $1 \%$ acid alcohol for $3 \mathrm{~s}$ and alkaline alcohol for another 3 seconds. Sections were further counterstained with Eosin for $1 \mathrm{~min}$. The sections were finally rinsed in distilled water, dehydrated in ascending grade of absolute alcohol, cleared in xylene and mounted with DPX.

For the PAS, the sections where deparaffinised hydrated and immersed in Periodic Acid Solution for 5mins. It was rinsed under distilled water and further immersed in Schiff's reagent for 15 minutes. After which, it was rinsed in running tap water for 5 mins, counterstained in Hematoxylin solution, Gil No. 3 for 90 seconds, rinsed in running tap water, dehydrated, cleared and mounted. Amscope 40X-2500X Digital binocular photomicroscope fitted with a 10MP microscope digital camera was used to take photomicrographs of all the sampled tissues.

\section{RESULTS AND DISCUSSION}

\section{Ovary}

The ovaries in the $1^{\text {st }}$ trimester was observed to have an external tunica albuginea as represented in Plates 1 and 2 after which, is the peripheral cortical and inner medullary zones. The two zones were not distinct. The cortical connective tissue was less dense than the medullary zone and hilus. The cortical zone had few and scanty follicular cells within the tissue stroma. It also contained lots of collagen fibre. The medullary zone had few arterioles, venules and lymphatic vessels (Plates 1 and 2).

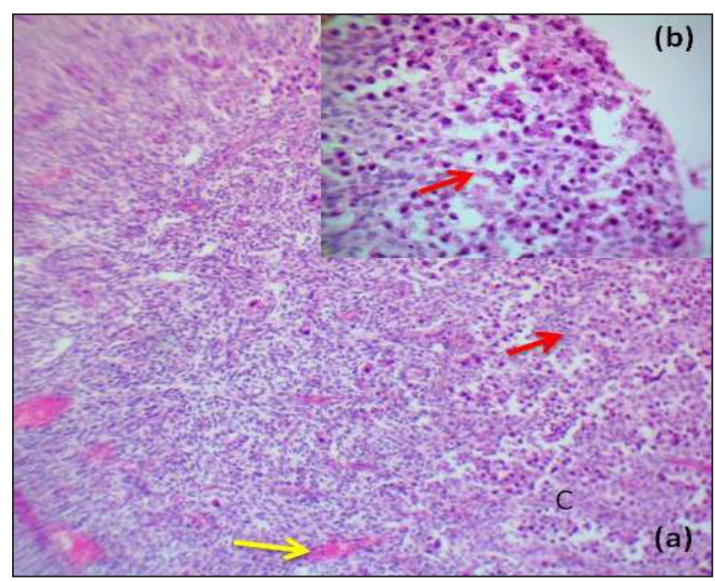

Plate 1: Photomicrograph in cross section of $1^{\text {st }}$ trimester Camelus dromedarius ovary indicating $\mathrm{C}$-cortex, blood vessels (yellow arrow) and connective tissue stroma (red arrows) (a) $\mathrm{H} \& \mathrm{E} x 40$ (b) H\&E x400

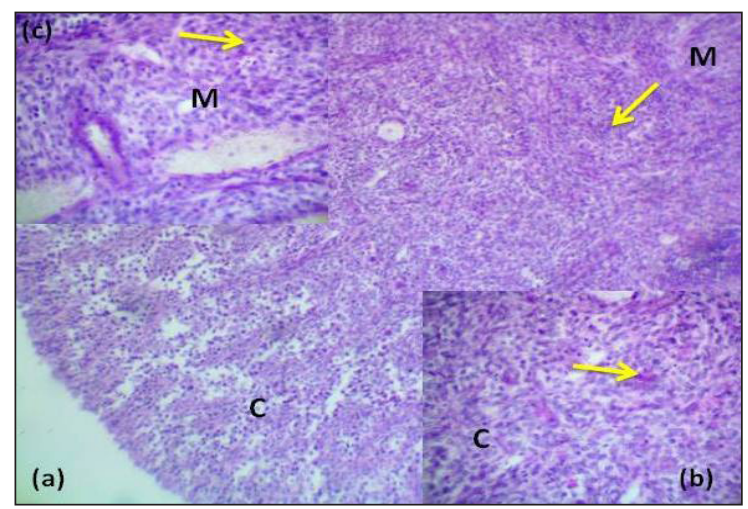

Plate 2: Photomicrograph in cross section of 1st trimester Camelus dromedarius ovary indicating blood vessels (yellow arrow), M-medulla, C-cortex (a) PAS x40 (b) PAS x400 (c) PAS $\mathrm{x} 400$ 
The $2^{\text {nd }}$ trimester had a more distinct demarcation between the cortex and medulla. The cortical zone had more follicular and primordial cells few primary follicles. The medullar zone bears a more distinct stratum vasculare with numerous arterioles, venules and lymphatic vessels (Plates 3 and 4 ). The $3^{\text {rd }}$ trimester bears more distinct zones, with the cortical having more cells, the primary follicles increased in number, and maturing secondary follicles were also observed (Plates 5 and 6).

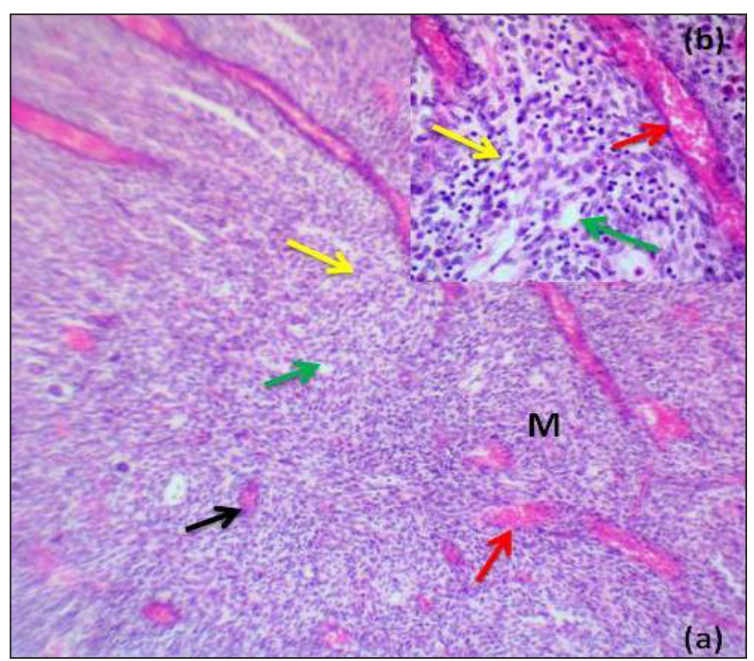

Plate 3: Photomicrograph in cross section of $2^{\text {nd }}$ trimester Camelus dromedarius ovary indicating venules (red arrows), arterioles (black arrow), lymphocytes (green arrow), connective tissue stroma (yellow arrow), and M-medulla (a) H\&E x40 (b) $\mathrm{H} \& \mathrm{E}$ x 400

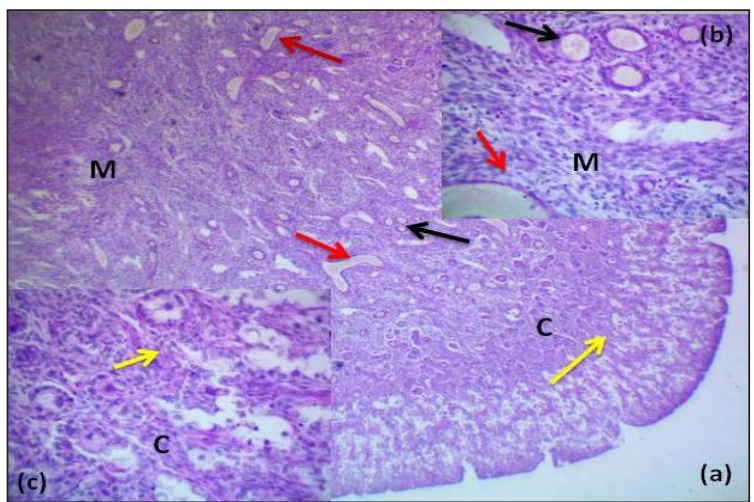

Plate 4: Photomicrograph in cross section of $2^{\text {nd }}$ trimester Camelus dromedarius ovary indicating venules (red arrows), arterioles (black arrow), connective tissue stroma (yellow arrow), C- cortex and M-medulla (a) PAS x40 (b) PAS x400 (c) PASx 400

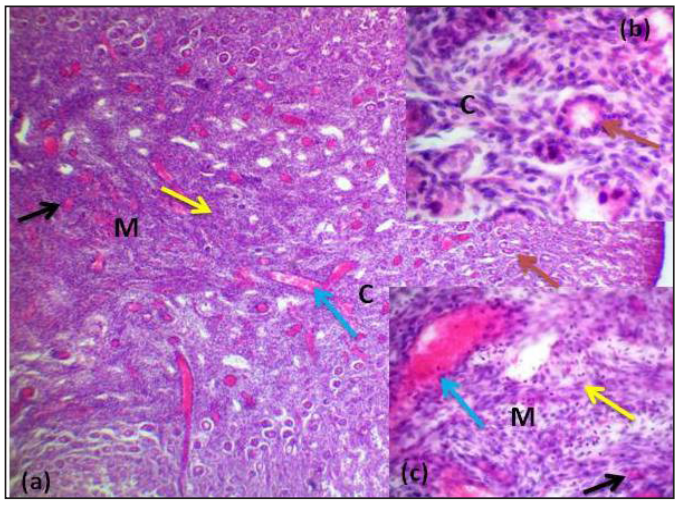

Plate 5: Photomicrograph in cross section of $3^{\text {rd }}$ trimester Camelus dromedarius ovary indicating venules (blue arrows), arterioles (black arrow), primordial follicles (brown arrow), connective tissue stroma (yellow arrow), C- cortex and M-medulla (a) H\&E x40 (b) H \& E x400 (c) H \&E x400

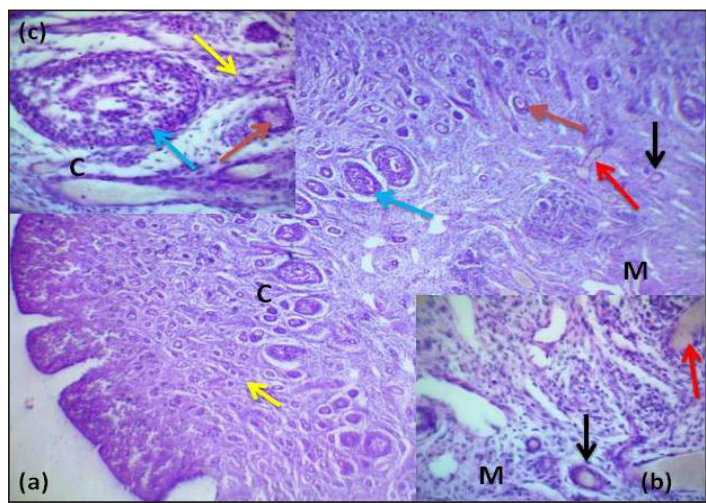

Plate 6: Photomicrograph in cross section of $3^{\text {rd }}$ trimester Camelus dromedarius ovary indicating venules (red arrows), arterioles (black arrow), early primary follicles (brown arrow), connective tissue stroma (yellow arrow), C- cortex and M-medulla (a) PAS x40 (b) PAS x400 (c) PAS x400.

\section{Oviduct}

The $1^{\text {st }}$ trimester oviduct of Camelus dromedarius fetus was seen to have the typical four layers; the mucosa, sub mucosa, muscularis and the serosa. The mucosa has longitudinal folds branching into the lumen (Plates 7 and 8). The epithelial lining was seen to be pseudostratified cuboidal epithelium. By the $2^{\text {nd }}$ trimester the muscular layer was observed to have more distinct layers of the typical circular and outer longitudinal layers. By the third trimester, the fimbriae appeared with more folds (Plates 9 and 10). 


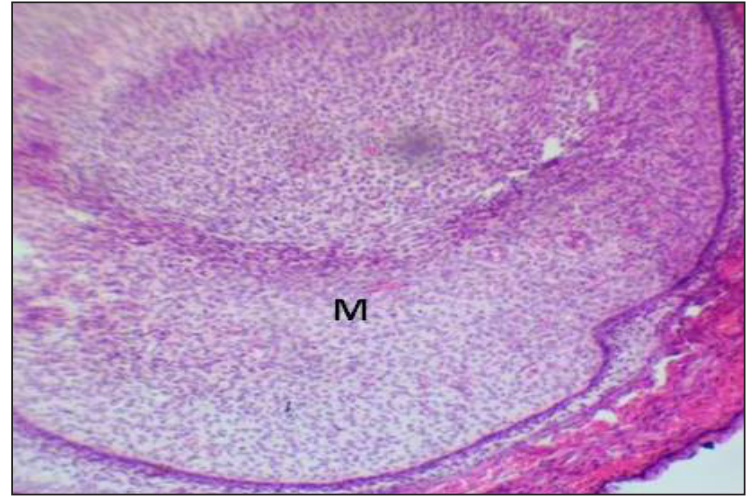

Plate 7: Photomicrograph in cross section of $1^{\text {st }}$ trimester Camelus dromedarius oviduct indicating M-mucosa. H \& E $\mathrm{x} 100$

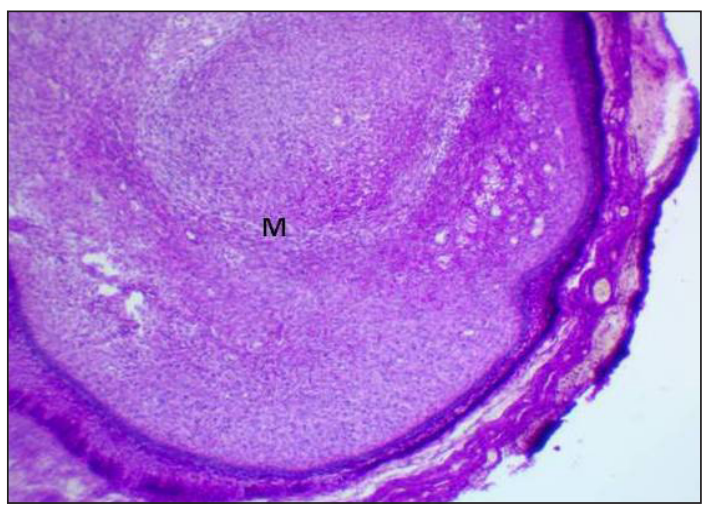

Plate 8: Photomicrograph in cross section of $1^{\text {st }}$ trimester Camelus dromedarius oviduct indicating M-mucosa. PAS x100

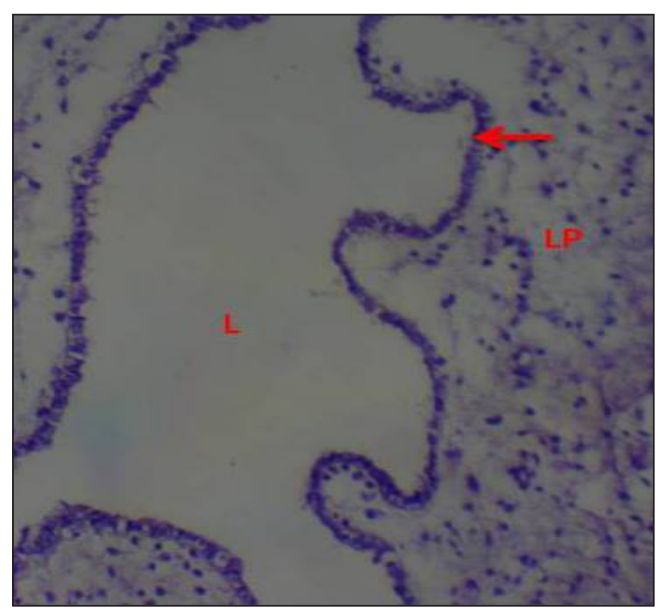

Plate 9: Photomicrograph in cross section of $2^{\text {nd }}$ trimester Camelus dromedarius oviduct indicating L-Lumen, LP- Lamina propria, red arrow as epithelium. H \& E x400

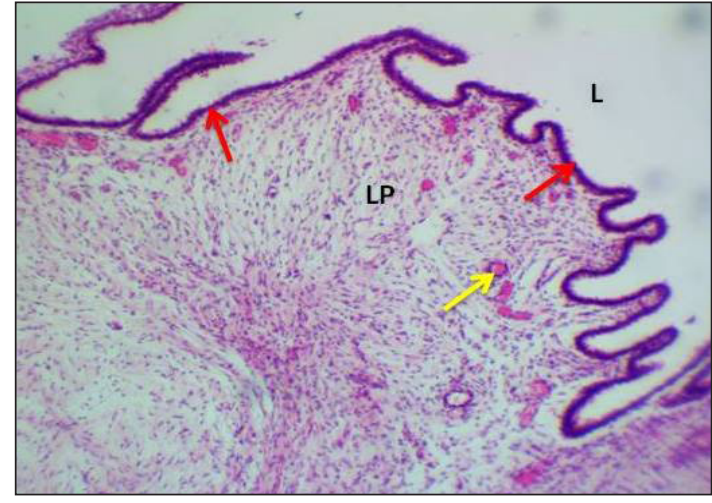

Plate 10: Photomicrograph in cross section of $3^{\text {rd }}$ trimester Camelus dromedarius oviduct indicating L-Lumen, LP- Lamina propria, red arrow as epithelium and yellow arrow as blood vessel. H \& E x100

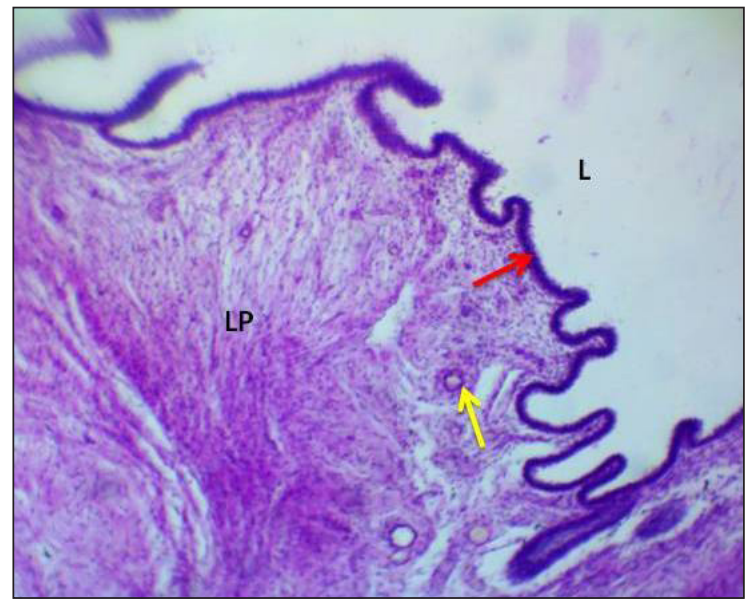

Plate 11: Photomicrograph in cross section of $3^{\text {rd }}$ trimester Camelus dromedarius oviduct indicating L-Lumen, LP- Lamina propria, red arrow as epithelium and yellow arrow as blood vessel. PAS x100

In this study, the fetal differentiation of the ovaries in the $1^{\text {st }}$ trimester was observed to have the cortical connective tissue to be less dense than the medullary zone and hilus. This is similar to the findings of Sawyer et al. (2002) in sheep fetus, Harshan et al. (1994) and Banankhojasteh et al. (2006) in fetal goat. The cortical zone had few and scanty follicular cells within the tissue stroma which is contrary to the findings of Aruna et al. (2017) on goat fetal ovaries. This could be due to specie difference. The $2^{\text {nd }}$ trimester had a more distinct demarcation between the cortex and medulla. The medullar zone in this study was observed to have a distinct stratum vasculare with 
numerous arterioles, venules and lymphatic vessels. The numerous vascular supplies could be important in the differentiation of the ovarian development as suggested by Aruna et al. (2017) in fetal goat ovaries.

The $3^{\text {rd }}$ trimester bears more distinct zones, with the cortical having more cells, the primary follicles increased in number, and maturing secondary follicles were also observed in this study. This could be attributed to the fact that the ovarian follicles are well-established during intrauterine life or early in neonatal life of all mammals as suggested by Gosden (2005).

The $1^{\text {st }}$ trimester oviduct of fetal Camelus dromedarius was observed to have the typical four layers, the mucosa, sub mucosa, muscularis and the serosa. This was in accordance with the observations of Bacha and Bacha (2012), Abiaezute et al. (2017) and Mokhtar (2015). The mucosa was observed to have longitudinal folds branching into the lumen. The epithelial lining was observed to be pseudostratified cuboidal epithelium which was in line with the observation s made by Ernst et al. (2011). By the $2^{\text {nd }}$ trimester the distinct muscular layers observed was contrary to discovery of Ernst et al. (2011) who described the mucosa layer to blend with the muscularis in the mid trimester, thus no distinct demarcation due to the blended nature of both connective tissue stroma. By the third trimester, the fimbriae appeared with more folds.

\section{CONCLUSION}

In conclusion, the structures of the ovary and oviduct can be added to the existing literature as similarities are found when compared to that of other ruminants. Further studies are required to establish the Ultrastructure of the ovarian follicles and oviduct in the camel fetuses.

\section{REFERENCES}

Abiaezute, C.N., Nwaogu, I.C. and Igwebuike, U.M. 2017. Evaluation of the morphological features of the uterine tubes during postnatal development in West African Dwarf goats (Capra hircus). Vet. Res. Forum, 8(1): 1-6.

Albaghdady, E. 2006. Anatomical and histological study of female genital system from six months to six years in Iraqi she-Camel (Camelus dromedarius). PhD Thesis, Department of Veterinary Anatomy and Histology, University of Bagdad.

Al-Juboori, A. 2016. Reproduction in camels. https://tinyurl. com/yxqf3yyr. Accessed on October 4, 2018.
Aruna, K.G., Rooh, U.A. and Sadasiva, R.K. 2017. Morphometric and histological characterization of goat fetal ovaries. Dairy Vet. S. J., 3(1): 1-7.

Bacha, W.J. and Bacha, L.M. 2012. Color Atlas of Veterinary Histology ( $3^{\text {rd }}$ Ed). Oxford, OX4 2DQ, UK: Wiley-Blackwell.

Banankhojasteh, S., Ranjbar, R. and Alboghobeish, N. 2006. Sex differentiation in goat fetus. Iran J. Vet. Res., 7(2): 65-69.

Bancroft, M.G. 2002. Theory and Practice of Histological Techniques. Churchill Livingstone, London, pp. 593-620.

Ernst, L., Ruchelli, E.D. and Huff, D.S. 2011. Color Atlas of Fetal and Neonatal Histology. Springer. Retrieved from https://books.google.com.ng/books?id=O_8wDxgxbk8C $\& \mathrm{dq}=$ fetal + bulbourethral + gland + histology $\&$ source $=$ gbs navlinks_s

Faye, B. 2015. Role, distribution and perspective of camel breeding in the third millennium economies. Emir. J. Food Agric., 27(4): 318-327.

Gosden, R.G. 2005. Growth and development of mammalian oocytes. In Book Growth and development of mammalian oocytes. City: University of Leeds.

Habel, R. 1970. Habel's Guide to the Dissection of Domestic Ruminants ( $2^{\text {nd }}$ ed.). Ithaca, New York.

Harshan, K.R., Yashwant, S. and Sharmam, D.N. 1994. Sex differentiation and development of ovary in the prenatal goat (Capra hircus). J. Vet. Ani. Sci., 25: 136-140.

Mokhtar, D.M. 2015. Microscopic and histochemical characterization of the bovine uterine tube during the follicular and luteal phases of estrous cycle. J. Microsc. Ultrastruct, 3(1): 44-52.

Sawyer, H.R., Smith, P., Heath, D. A., Juengel, J.L., Wakefield, S.J. and Mcnatty, K.P. 2002. Formation of ovarian follicles during fetal development in sheep. Bio. Repro., 66: 11341150 .

Villalon, M., Velasquez, L. and Croxatto, H. 1998. Oocyte and embryo transport. In: Ernest K, Jimm DN (Eds). Encyclopedia of reproduction. San Diego, USA: Academic Press, pp. 459468.

Volpato, G. and Howard, P. 2014. The material and cultural recovery of camels and camel husbandry among Sahrawi refugees of Western Sahara. Res. Pol. Prac., 4: 7. 
